\title{
A Case Study of Prazosin-Induced Hypothermia
}

\author{
Danae DiRocco, Seshagiri Rao Doddi* \\ Department of Psychiatry, University of Maryland School of Medicine, Baltimore, USA \\ Email address: \\ Danae.dirocco@gmail.com (D. DiRocco), sdoddi@som.umaryland.edu (S. R. Doddi) \\ ${ }^{*}$ Corresponding author
}

\section{To cite this article:}

Danae DiRocco, Seshagiri Rao Doddi. A Case Study of Prazosin-Induced Hypothermia. American Journal of Psychiatry and Neuroscience. Vol. 9, No. 3, 2021, pp. 115-117. doi: 10.11648/j.ajpn.20210903.17

Received: July 14, 2021; Accepted: August 16, 2021; Published: August 31, 2021

\begin{abstract}
A case report of prazosin-induced hypothermia in a treatment-naive patient with PTSD. A 65-year-old woman with bipolar disorder and nightmares resulting from previous traumas was admitted to an inpatient psychiatry unit for mixed state hypomania and depression with suicidal ideation. Prazosin $1 \mathrm{mg}$ was started to help manage nightmares and the patient developed asymptomatic hypothermia with a low of 33.5C after 5 days of therapy. After internal medicine and endocrinology consults and appropriate testing did not result in an explanation, prazosin was stopped and her temperature returned to normal. A rechallenge of prazosin again resulted in a temperature decrease and was then discontinued. Hypothermia is not a reported side effect of prazosin in humans, though one previous case study reports hypothermia with a $20 \mathrm{mg}$ total daily dose in the treatment of a patient with hypertension. Animal studies indicate two possible mechanisms of action including 1) increased heat dissipation from skin by inhibition of non-shivering thermogenesis and decreased metabolic rate and 2) temperature increases upon rapid eye movement sleep deprivation (REMSD) in rats by increasing noradrenaline. Prazosin modulates REMSD-induced changes in body temperature in rats by blocking the effects of noradrenaline in postsynaptic receptors. To our knowledge, this is only the second reported case of hypothermia induced by prazosin.
\end{abstract}

Keywords: PTSD, Prazosin, Hypothermia

\section{Introduction}

Prazosin is a synthetic piperazine derivative. It is an alpha1 blocker, inhibits postsynaptic alpha-adrenergic receptors, causing arterial and venous dilatation and subsequent decrease in blood pressure [1]. Prazosin is primarily approved by FDA as an anti-hypertensive. To a lesser extent, this agent also decreases the tone of the bladder sphincter, thereby allowing the opening of the bladder into the urethra and thus relieving the urinary conditions associated with benign prostatic hypertrophy [2]. Other non-FDA approved uses include heart failure [3], prevention of Raynaud's phenomenon [4] and for treatment of nightmares associated with Post-traumatic Stress Disorder (PTSD) [5]. Several published studies support the usefulness of prazosin in PTSD for the management of associated nightmares but showed mixed results in randomized controlled trials [6-12]. As per drug labeling information, most frequent reactions associated with prazosin hydrochloride therapy are dizziness $10.3 \%$, headache $7.8 \%$, drowsiness $7.6 \%$, lack of energy $6.9 \%$, weakness $6.5 \%$, palpitations $5.3 \%$, and nausea $4.9 \%$. Less frequent (1-4\%) are vomiting, diarrhea, constipation, edema, orthostatic hypotension, dyspnea, syncope, vertigo, depression, nervousness, rash, urinary frequency, blurred vision, reddened sclera, epistaxis, dry mouth, nasal congestion. Rare (fewer than 1\%) side effects are abdominal discomfort and/or pain, liver function abnormalities, pancreatitis, tachycardia, paresthesia, hallucinations, pruritus, alopecia, lichen planus, incontinence, impotence, priapism, tinnitus, diaphoresis, fever, positive ANA titer, arthralgia. Hypothermia is not one of the listed side effects of prazosin. Literature review revealed one case report of hypothermia with prazosin $20 \mathrm{mg}$ (10mg bid) dose used for treatment of hypertension. In this case study, the patient was treated as an inpatient with gradually increasing doses of prazosin up to $10 \mathrm{mg}$ bid. Her rectal temperature at admission was $37 \mathrm{C}$ but began to decrease 3 days after therapy was started. Her temperature then stabilized around 35.6C. Investigations into the cause of her hypothermia including thyroid levels, were done but all within normal levels. Prazosin was stopped and temperature returned to normal. A rechallenge of prazosin 
one week later resulted in her temperature falling to $35 \mathrm{C}$ and was then stopped [13]. The following paper reports a case of prazosin induced hypothermia with $1 \mathrm{mg}$ dose used for treatment of nightmares in a patient with symptoms of PTSD.

\section{Case Report}

A 65-year-old African American woman with bipolar disorder was admitted to inpatient psychiatry for mixed state hypomania and depression with suicidal ideation. Significant medical history included heart failure, HTN, morbid obesity and deep vein thrombosis. She also reported a history of multiple traumas and subsequent nightmares. Lamotrigine and oxcarbazepine were initiated, and home medications continued (amlodipine, candesartan, hydrochlorothiazide). On admission, comprehensive laboratory testing and vital signs were normal except for mild leukopenia and blood pressure of 141/87. Temperature was 36.4C.

Prazosin $1 \mathrm{mg}$ nightly was started on hospital day 4 for nightmares. She denied a history of therapy with this medication and medical record review did not indicate any previous trials. Within 5 days she developed hypothermia with an oral temperature of $33.7 \mathrm{C}$ and otherwise stable vital signs. At that time the patient was asymptomatic. She was warmed with blankets, warm packs and hot beverages, leading her to complain of feeling hot with these interventions but without change in her temperature which was 34.3C (oral) and 34.7C (rectal).

Internal Medicine and Endocrinology were consulted when hypothermia persisted after 2 days. Adrenal insufficiency was considered as a cause and a cosyntropin stimulation test was completed and found to be normal.

Prazosin was discontinued on day 10 after 6 days of treatment. Two days after cessation, hypothermia resolved (36.2C). Prazosin was re-challenged after 3 days and temperature dropped to 34.3C. Prazosin was discontinued and not prescribed on discharge.

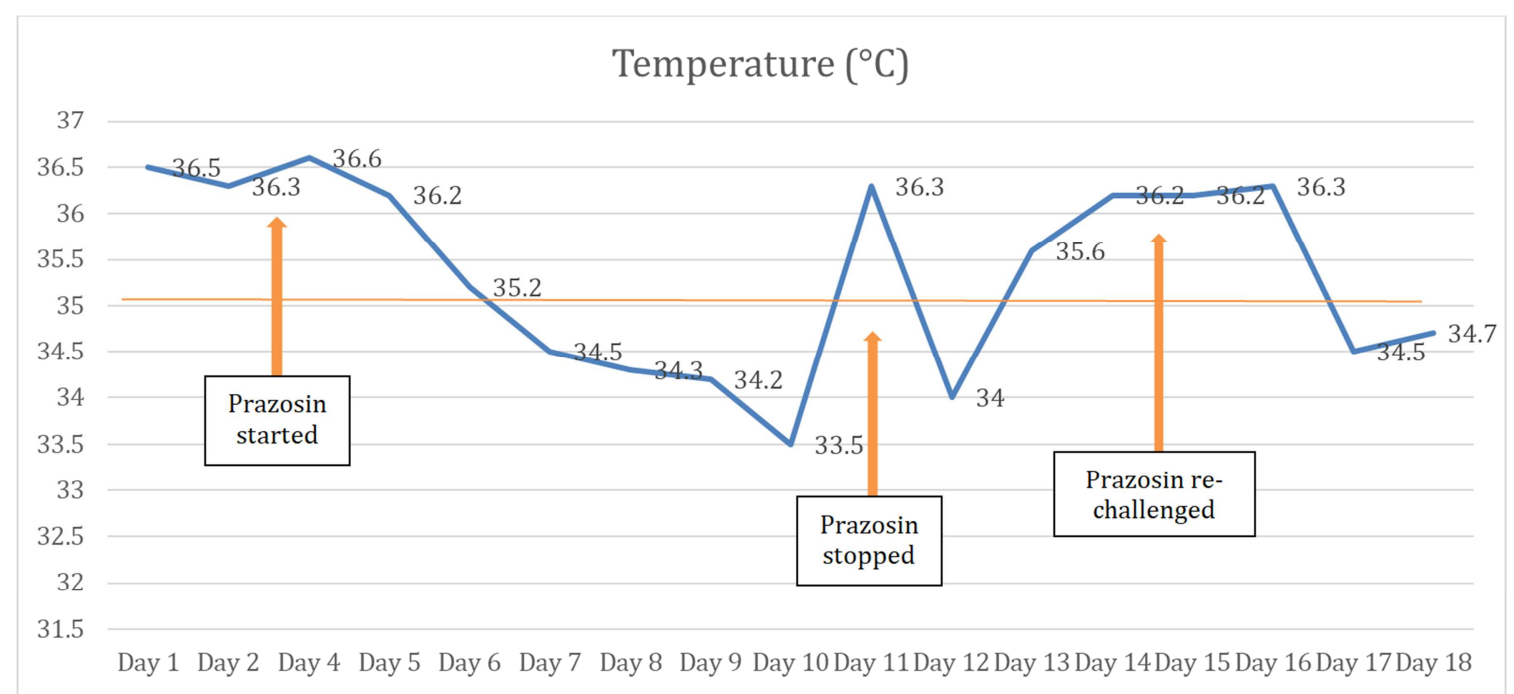

Figure 1. Graph of temperatures during admission. Temperatures were orally taken and the first number in the morning was used for each day. Day 3 had no temperature data recorded so is left off this graph. $35^{\circ} \mathrm{C}$ is the cut off for low end of normal human temperature and is marked to delineate normal from hypothermic temperatures.

\section{Discussion}

Review of the available literature showed one case report [13] of hypothermia in a patient treated with prazosin $10 \mathrm{mg}$ daily for hypertension and hypothermia resolved with removal of the drug. In the report by Wollersheim et al. [14], three patients with either hypertension or Raynaud's phenomenon were each treated with one of the three vasodilatory drugs: prazosin, nifedipine or prostacyclin. A decrease in rectal body temperature was noted in one of these three patients, though drug was not specified. It is not clear if the patient that suffered hypothermia was on prazosin or one of the other two medications and further clarification could not be obtained. Otherwise, no articles about prazosin induced hypothermia in humans could be found in the literature aside from a single case study in a patient on high dose prazosin for hypertension. The mechanism of action, how prazosin effects body temperature, is unknown. A possible explanation from animal models is that temperature increases upon rapid eye movement sleep deprivation (REMSD) in rats by increasing noradrenaline [15]. Prazosin modulates REMSD-induced changes in body temperature in rats by blocking the effects of noradrenaline in postsynaptic receptors [15]. Other animal studies have hypothesized that prazosin's action on hypothermia is mediated through increased heat dissipation from skin which may be modulated by inhibition of non-shivering thermogenesis and decreasing metabolic rate [16-17].

\section{Conclusion}

This patient experienced asymptomatic hypothermia with prazosin $1 \mathrm{mg}$ that resolved with medication cessation. 
Hypothermia is not a listed side effect of prazosin. This patient had potentially confounding comorbid conditions as well as trials of other new medications. Appropriate consultants offered advice on possible alternative causes of hypothermia, but none were found. The trial and re-challenge of prazosin with a return of hypothermia indicates that this was likely related to a little-known mechanism of action on thermoregulation in humans.

\section{References}

[1] Graham RM, Oates HF, Stoker LM, Stokes GS. Alpha blocking action of the antihypertensive agent, prazosin. J Pharmacol Exp Ther. 1977 Jun; 201 (3): 747-52.

[2] Milroy E: Clinical overview of prazosin in the treatment of prostatic obstruction. Urol Int 1990; 45 (suppl 1): 1-3.

[3] Rouleau JL Warnica JW, Burgess JH. Prazosin and Congestive Heart Failure: Short- And Long-Term Therapy. Comparative Study. Am J Med 1981 Jul; 71 (1): 147-52

[4] Wollersheim H \& Thien T: Dose-response study of prazosin in Raynaud's phenomenon: clinical effectiveness versus side effects. J Clin Pharmacol 1988; 28: 1089-1093.

[5] Ahmadpanah M, Sabzeiee P, Hosseini SM, et al: Comparing the effect of prazosin and hydroxyzine on sleep quality in patients suffering from posttraumatic stress disorder. Neuropsychobiology 2014; 69 (4): 235-242.

[6] Fletcher B. Taylor, Patti Martin, Charles Thompson, Judi Williams, Thomas A. Mellman, Christopher Gross, Elaine R. Peskind, and Murray A. Raskind. Prazosin Effects on Objective Sleep Measures and Clinical Symptoms in Civilian Trauma Posttraumatic Stress Disorder: A Placebo-Controlled Study BIOL PSYCHIATRY 2008; 63: 629-632.

[7] Heather R Taylor, Maisha Kelly Freeman, Marshall E Cates Prazosin for Treatment of Nightmares Related to Posttraumatic Stress DisorderAmj Health Syst Pharm. 2008 Apr 15; 65 (8): 716-22.

[8] Ismene L Petrakis, Nitigna Desai, Ralitza Gueorguieva, Albert Arias, Erin O'Brien, J Serrita Jane, Kevin Sevarino, Steven
Southwick, Elizabeth Ralevski. Prazosin for Veterans with Posttraumatic Stress Disorder and Comorbid Alcohol Dependence: A Clinical Trial. Alcohol Clin Exp Res. 2016 Jan; 40 (1): 178-86 doi: 10.1111/acer.12926. Epub 2015 Dec 19.

[9] M. A. Raskind, E. R. Peskind, B. Chow, C. Harris, A. DavisKarim, H. A. Holmes, K. L. Hart, M. McFall, T. A. Mellman, C. Reist, J. Romesser, R. Rosenheck, M.-C. Shih, M. B. Stein, R. Swift, T. Gleason, Y. Lu, and G. D. Huang. Trial of Prazosin for Post-Traumatic Stress Disorder in Military Veterans. $n$ engl j med. February 8, 2018378 (6): 507-17.

[10] MAJ Christine Maura Daly, MC USA; LTC Michael E. Doyle, MC USA; Murray Radkind, MD, Elaine Raskind, MD; MAJ Colin Daniels, MC USA. Clinical Case Series: The Use of Prazosin for Combat-Related Recurrent Nightmares among Operation Iraqi Freedom Combat Veterans. MILITARY MEDICINE, 170, 6: 513, 2005.

[11] Matthew R Dierks, Joseph K Jordan, Amy Heck Sheehan. Prazosin Treatment of Nightmares Related to Posttraumatic Stress Disorder. Ann Pharmacother Jun; 41 (6): 1013-7.

[12] Elaine R. Peskind, MD, Lauren T. Bonner, MD, David J. Hoff, PA-C, and Murray A. Raskind, MD. Prazosin Reduces Trauma-Related Nightmares in Older Men with Chronic Posttraumatic Stress Disorder. J Geriatr Psychiatry Neurol 2003; 16: 165-171.

[13] Leeuw PWD, Birkenhager WH. Hypothermia: a possible side effect of prazosin. BMJ. 1980; 281 (6249): 1181-1181.

[14] Wollersheim H, Berden J, Thien T. Decreased rectal body temperature induced by different vasodilatory drugs. Neth J Med. 1989; Apr; 34 (3-4): 189-93.

[15] Jaiswal M and Mallick B. Prazosin modulates rapid eye movement sleep deprivation induced changes in body temperature in rats. J. Sleep Res. (2009) 18, 349-356.

[16] Zarrindast, M.-R., Sadeghi, S. and Sahebgharani, M. (2003), Influence of $\alpha$-Adrenoceptor Agonists and Antagonists on Imipramine-Induced Hypothermia in Mice. Pharmacology \& Toxicology, 93: 48-53. https://doi.org/10.1034/j.16000773.2003 .930107 .

[17] Matuszek M, Szreder Z, Korolkiewicz Z: Effects of prazosin onmetabolism and body temperature in normothermic rabbits. Pol J Pharmacol Pharm 1986. 